\section{Root Growth, Free Amino Acids, and Carbohydrates of Tall Fescue in Response to Soil Salinity}

\author{
Yong Yang ${ }^{1}$ \\ College of Agriculture, Hunan Agricultural University, Changsha, Hunan \\ 410128, P.R. China; and Golf College, Hunan International Economics \\ University, Changsha, Hunan 410205, P.R. China
}

\author{
Xueyong Liu ${ }^{1}$ \\ Golf College, Hunan International Economics University, Changsha, Hunan \\ 410205, P.R. China
}

\author{
Yuanli Jiang \\ Hunan Biological and Electromechanical Polytechnic, Changsha, Hunan \\ 410127, P.R. China

\section{Zuoxiang Xiang ${ }^{2}$ and Qingguo $\mathbf{X u}^{2}$ \\ College of Agriculture, Hunan Agricultural University, Changsha, Hunan 410128, P.R. China}

\section{Na Zhao and Bichao Shu \\ Golf College, Hunan International Economics University, Changsha, Hunan 410205, P.R. China}

Additional index word. saline soil, root activity, free amino acids, carbohydrate, tall fescue

\begin{abstract}
Salt-affected soils may retard plant growth and cause metabolic alterations. The objective of this study was to investigate the effect of salinity in deep soil on root growth and metabolic changes of tall fescue (Festuca arundinacea). Tall fescue seeds (cv. Houndog V) were planted in polyvinylchloride (PVC) tubes $(9 \mathrm{~cm}$ diameter $\times 45 \mathrm{~cm}$ long) for 2 months with three treatments of growth substances: (1) control, filled with peat-sand mixtures for full tubes $(40 \mathrm{~cm}$ height, sand:organic fertilizers $=7: 3, \mathrm{w} / \mathrm{w}) ;(2)$ T20, $20 \mathrm{~cm}$ saline soil covered with $20 \mathrm{~cm}$ organic fertilizers and sand; (3) $T 30,30 \mathrm{~cm}$ saline soil covered with $10 \mathrm{~cm}$ organic fertilizers and sand. Turf quality and vertical shoot growth rate (VSGR) significantly decreased in $\mathrm{T30}$, but not for $\mathrm{T20}$, when compared with the control. Salinity in deep soil obviously inhibited the root growth as indicated by the lower root length, root projected area, root diameter, root fresh, and dry weight, but increased the level of amino acids (Asp, Glu, Ser, Gly, etc.) and soluble sugars (glucose, fructose, sucrose). Root activity in top layer $(0-10 \mathrm{~cm})$ of saline soil increased while decreased in deeper layer $(20-40 \mathrm{~cm})$ when compared with the control. The increase of root activity and free amino acids in roots from upper layer and the accumulation of soluble sugars in roots from deeper soil layer under salinity conditions were the adaptive responses and regulative mechanisms that for supporting the above-ground plant growth in tall fescue when exposed to deep soil salinity conditions. These results also suggested that a $20 \mathrm{~cm}$ of improved mixture of organic fertilizers with sand on the top of saline soil could be sufficient to supply basic space for the normal growth of turfgrass with regular spray irrigation.
\end{abstract}

Saline soils are widely distributed all over the world, especially in the arid and semiarid areas and coastland (Cheong and Yun, 2007). Soil salinity may have a profound impact on plant growth. Previous studies have reported that soil salinization influences on the

Received for publication 31 Dec. 2014. Accepted for publication $17 \mathrm{Feb} .2015$.

This work was financially supported by the Changsha Municipal Science and Technology Project (K1403026-31).

${ }^{1}$ These authors contributed equally.

${ }^{2}$ To whom reprint requests should be addressed; e-mail turfxzx@163.com or huxu0309@aliyun.com. growth, development and differentiation of plants, and causes a low productivity of agricultural crops and grasses (Koca et al., 2007; Munns, 2002; Zhu, 2001). Salinity stress in deeper soil is extremely common in the field, whereas the upper soil with remediation may be sufficient for uptake by the plant with regular irrigation (Tejada et al., 2006). However, the physiological mechanisms underlying plant adaptation to salinity in deeper soil has not been vividly comprehended.

High soil salinity due to the accumulation of neutral salts such as $\mathrm{NaCl}$ interferes with normal plant growth, development and dif- ferentiation. $\mathrm{NaCl}$ stress affects plants through the direct action of $\mathrm{Na}^{+}$or $\mathrm{Cl}^{-}$ions and the creation of osmotic stress (Hasegawa et al., 2000; Munns, 2005). The severe effects of soil salinity can directly damage plant roots by disrupting the ionic balance and mineral nutrition (Hasegawa et al., 2000). In addition, salinity alters the availability of micronutrients and results in micronutrient deficiency in plants (Turkan and Demiral, 2009). The degree of this damage depends on its influence on the plant physiological and biochemical processes and the potential of the plant to adapt/tolerate salinity stress (Munns and Tester, 2008; Takahashi et al., 2001; Zhu, 2001). Usually, plant root systems are the first organs to experience and respond to high salinity stimuli. To survive in saline conditions, plant roots have evolved numerous physiological and metabolic adjustments to adapt/tolerate salinity stress, which include the changes of free amino acids and carbohydrates metabolism.

Free amino acids are fundamental compositions in the processes of protein and other growth substances synthesis, which are vital for plant stress tolerance by modulating stomatal conductance, detoxifying reactive oxygen species, and regulating intracellular ion transport (Parida and Das, 2005; Rai, 2002; Szabados and Savoure, 2010). Alternatively, the accumulation of free amino acids could improve plant stress tolerance through osmotic adjustment (Serraj and Sinclair, 2002), and/or serve as storage forms of carbon and nitrogen for future use in absence or less stressful environments (Greenway and Munns, 1980). About 18 free amino acids were substantiated its functions in the physiological and biochemical processes. Glutamic acid and glycine were the fundamental metabolites in the chlorophyll synthesis processes (Kannangara et al., 1988). Proline was considered to have the capability of stabilizing the protein and membranes structures against the adverse effects of drought, salinity and extreme temperatures (Szabados and Savoure, 2010; Verslues and Sharp, 1999). Glycine, arginine, asparagine, and serine accumulated in spinach (Spinacia oleracea) and Coleus blumei Benth under salt stress (Gilbert et al., 1998; Martino et al., 2003). Asparagine and valine increased in bermudagrass under water stress (Barnett and Naylor, 1966). Kerkeb and Krämer (2003) demonstrated that asparagine and histidine could bind heavy metals as antidotes.

In plants, carbohydrates are synthesized from a series of complex photosynthetic reactions. Plant growth, development and differentiation depend mainly on carbohydrate metabolisms, which include the synthesis of sucrose, fructose, and glucose (Hasegawa et al., 2000). Higher carbohydrates concentration before and under abiotic stress period may indicate better tolerance (Kafi et al., 2003). The biochemical breakdown of carbohydrates can supply energy and metabolites to participate in the biosynthetic processes (Rolland et al., 2006). Soluble sugars, such as glucose, fructose, and sucrose, 
have been widely considered to be typical osmoprotectants, stabilizing cellular membranes, scavenging radical reactive oxygen species, and serving as carbon sinks in plants (Farooq et al., 2009; Kerepesi and Galiba, 2000; Parida and Das, 2005; Rolland et al., 2006).

Free amino acids and carbohydrates accumulation may assist to maintain the ionic balance homeostasis, removal of free radicals, and stabilization of organelles and macromolecules (Gilbert et al., 1998). Currently, there is little information on free amino acids and carbohydrates on plants to cope with salinity under deep soil conditions, especially in tall fescue. Tall fescue, native to West Europe, North Africa, and Southwest Asia, is one of the most widely used cool-season turfgrasses in the northwest of China (Xiong et al., 2007). Rapid establishment makes tall fescue serve as a vanguard in combination with other turfgrasses on lawn, athletic field, and golf courses (Xing et al., 2007). Furthermore, tall fescue has good salinity tolerance, high regeneration, and tiller density (Wilkins and Humphreys, 2003). Consequently, it is a preferred perennial forage grass in temperate global regions. However, limited information is available about the effect of salinity in deep soil on the physiological metabolisms in tall fescue. The objectives of this study were to (1) estimate salinity effects on root activity and growth of tall fescue; (2) decipher salinity induced changes of free amino acids and soluble sugars in tall fescue roots exposed to salinity in deep soil.

\section{Materials and Methods}

Plant materials, growth conditions and treatment. Saline soil was collected from the coastland of Jiangshu province, China. The saline soils contain $2.5 \%$ total soluble salt, $0.45 \mathrm{~g} \cdot \mathrm{kg}^{-1}$ total $\mathrm{N}, 8.01 \mathrm{mg} \cdot \mathrm{kg}^{-1}$ available $\mathrm{P}$, $121.02 \mathrm{mg} \cdot \mathrm{kg}^{-1}$ available $\mathrm{K}, 6.86 \mathrm{~g} \cdot \mathrm{kg}^{-1}$ organic matter and with a $\mathrm{pH}$ of 8.02 . PVC tubes $(9 \mathrm{~cm}$ diameter, $42 \mathrm{~cm}$ depth) were divided into three layers according to the depth: upper $(0-10 \mathrm{~cm})$, middle $(10-20 \mathrm{~cm})$, and bottom $(20-40 \mathrm{~cm})$. The three layers of PVC tubes were filled with saline soil and the mixtures of sifted sand and organic fertilizers (decomposed swine manures) according to Figure 1. The bottom of the PVC tubes was covered by a nylon membrane to prevent leaching.

Tall fescue seeds (cv. Houndog V) were germinated on the three levels of saline soil $(0,20$, and $30 \mathrm{~cm}$ depth of saline soil) (three treatments). The three treatments were as follows: (1) $40 \mathrm{~cm}$ filled with mixtures of sand and organic fertilizers (decomposed swine manures) (w/w, sand:organic fertilizers $=7: 3$ ) as control; (2) $20 \mathrm{~cm}$ saline soil covered with $20 \mathrm{~cm}$ mixtures as T20; (3) $30 \mathrm{~cm}$ saline soil covered with $10 \mathrm{~cm}$ mixtures as T30 (Fig. 1). The saline-soil treatments were arranged in a randomized, complete block design with five replicates.

The plants were maintained on a daily air temperature of 18 to $22{ }^{\circ} \mathrm{C}$ along with

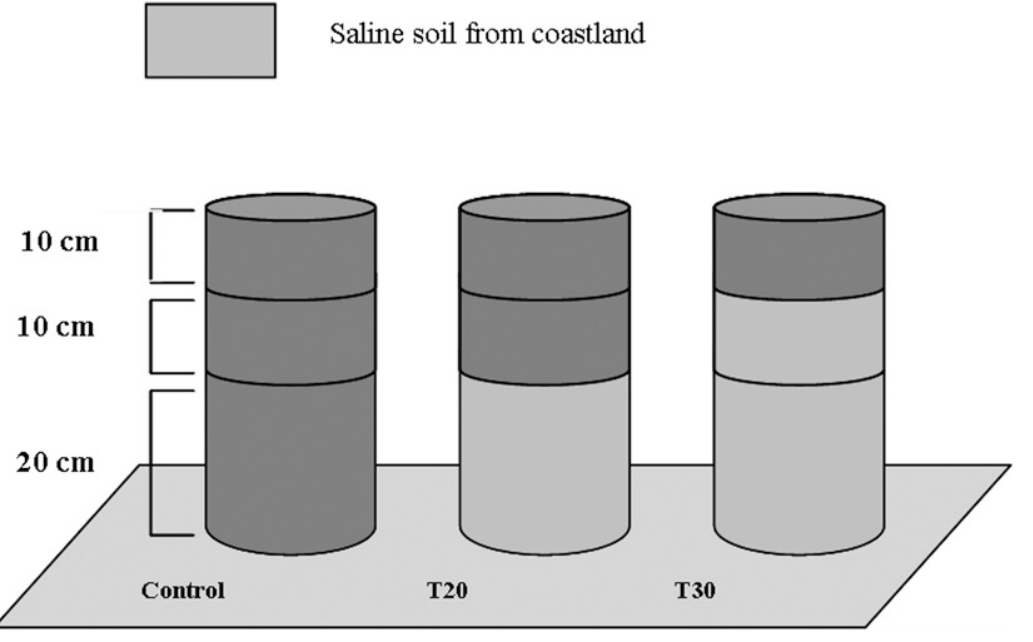

Fig. 1. Experimental design as follows. Polyvinylchloride tubes ( $9 \mathrm{~cm}$ diameter, $42 \mathrm{~cm}$ depth) were divided into three layers according to depths: upper, middle as well as bottom, both upper and middle were 10 $\mathrm{cm}$, and bottom for $20 \mathrm{~cm}$, the three segments were linked by rubberized fabric. Three treatments were performed in this study, $40 \mathrm{~cm}$ filled with mixtures of sand and organic materials (w/w sand:organic materials $=7: 3$ ) as control, $20 \mathrm{~cm}$ saline soil covered with $20 \mathrm{~cm}$ mixtures as T20, and $30 \mathrm{~cm}$ saline soil covered with $10 \mathrm{~cm}$ mixtures as T30. Every treatment takes five replicates.

a photosynthetic active radiation (PAR) of $350 \mu \mathrm{mol} \cdot \mathrm{m}^{-2} \cdot \mathrm{s}^{-1}$ and a $14 \mathrm{~h}$ photoperiod. The grasses were mowed every $3 \mathrm{~d}$ at a height of $6 \mathrm{~cm}$ after germination. The plants were watered every $3 \mathrm{~d}$ according to the daily evaporation. The half-strength Hoagland nutrient was sprayed at afternoon every $3 \mathrm{~d}$ (Hoagland and Arnon, 1950). After the establishment of root and canopy (2 months), rubberized fabric between the joint of PVC tubes was dilacerated and the PVC tubes were cut into three segments. Roots from different segments were washed with tap water and blotted dry with paper towel. Subsequently, roots were divided into three parts, one for the determination of root length and root activity, and the other were frozen in liquid $\mathrm{N}_{2}$ and stored at $-70{ }^{\circ} \mathrm{C}$ until further analysis of free amino acids. The third one were killed at $105{ }^{\circ} \mathrm{C}$ for $5 \mathrm{~min}$ and dried at $80^{\circ} \mathrm{C}$ for $48 \mathrm{~h}$ until constant weight. The dried root samples were used to determine the content of soluble sugars.

Measurements. Root length, root diameter, and root projected area were determined as described by Mohammad et al. (1998) with slight modifications. Fresh roots (about 1/6 of total roots) were rapid marinated by formalin-acetic acid (FAA) fixative. The consumption of FAA fixative and fixation time was according to the size and fraction void of the materials. In this study, the consumption of FAA fixative was $20 \mathrm{~mL}$ and fixation time was $24 \mathrm{~h}$. After $24 \mathrm{~h}$, the materials were taken out of the tubes and blotted dry by filter paper, and then colored by Coomassie brilliant blue (R-250) for $48 \mathrm{~h}$. The colored materials were flushed by tap water and blotted dry, and then laid uniformly on a clear glass panel, using a ruler as reference system before taking photos. Finally, Digimizer (software for photo analysis) was used to measure root length and root projected area. Total root length and root projected area were the sum of the three layers (top, middle, and bottom) of roots. Mean root diameter measurement corresponded to the following equation: average root diameter $=$ root projected area/root length.

The root activity was detected by TTC method according to Lutts et al. (2004). Briefly, $0.5 \mathrm{~g}$ of fresh roots were cut into pieces and quickly rinsed in deionized water containing $0.06 \%$ Tween 20 and incubated at $30{ }^{\circ} \mathrm{C}$ in darkness in tubes containing $6 \mathrm{~mL}$ of $0.5 \% \mathrm{TTC}$ in $50 \mathrm{~mm} \mathrm{~K}_{2} \mathrm{HPO}_{4}$, pH 7.0 for $20 \mathrm{~h}$. The colored root samples were blotted dry and rinsed in deionized water, then incubated in $10 \mathrm{~mL}$ of $95 \%$ ethanol at $60{ }^{\circ} \mathrm{C}$ for $4 \mathrm{~h}$ under gentle agitation during the extraction. The absorbance of the extract solution was recorded at $530 \mathrm{~nm}$ and root activity was calculated according to standard curve with following equation:

$$
\text { Root activity }=D /(w \times t)[\mu \mathrm{g} /(\mathrm{g} \cdot \mathrm{h})]
$$

where $\mathrm{D}$ represents the deoxidizing amount of the TTC $(\mu \mathrm{g})$; w is the fresh weight of roots $(\mathrm{g})$; $t$ stands for the time of coloration $(\mathrm{h})$.

Free amino acids were determined by the method of Zhang et al. (2012). Samples of $500 \mathrm{mg}$ fresh weight were frozen in liquid nitrogen and free amino acids were extracted with $1.5 \mathrm{~mL} \mathrm{HCl}(0.1 \mathrm{M})$ at $4{ }^{\circ} \mathrm{C}$ for $8 \mathrm{~h}$. The tubes containing the extract were centrifuged at $16,000 \times g$ for $10 \mathrm{~min}$ and the collected supernatant was centrifuged again at $16,000 \times g$ for $40 \mathrm{~min}$. The aqueous phase was obtained for HPLC analysis. Seventeen amino acids were separated on an Eclipse AAA column $(4.6 \times 150 \mathrm{~mm}, 5 \mu \mathrm{m})$ eluted at $40{ }^{\circ} \mathrm{C}$ with a gradient of solution A $\left(40 \mathrm{~mm} \mathrm{NaH} \mathrm{NaO}_{4}\right.$, $\mathrm{pH} 7.8)$ and buffer B [45\% (v/v) acetonitrile, $45 \%(\mathrm{v} / \mathrm{v})$ methanol, $\left.10 \%(\mathrm{v} / \mathrm{v}) \mathrm{H}_{2} \mathrm{O}\right]$ at a flow rate of $2.0 \mathrm{~mL} / \mathrm{min}$ with the following proportions of buffer B: $0 \mathrm{~min}, 0 \% ; 1.9 \mathrm{~min}$, $0 \%$; $18.1 \mathrm{~min}, 57 \%$; $18.6 \mathrm{~min}, 100 \%$; 22.3 min, $100 \%$; $23.2 \mathrm{~min}, 0 \%$; $30 \mathrm{~min} 0 \%$. 
Precolumn derivatization was made by the autosampler by mixing $0.5 \mu \mathrm{L}$ sample with $2.5 \mu \mathrm{L} \mathrm{H}_{3} \mathrm{BO}_{3}(0.4 \mathrm{M}, \mathrm{pH} 10.2), 0.5 \mu \mathrm{L}$ o-phtalaldehyde $\left(10 \mathrm{mg} \cdot \mathrm{mL}^{-1}\right), 0.5 \mu \mathrm{L}$ FMOC (5 mg. $\mathrm{mL}^{-1}$ ) and $14 \mu \mathrm{L} \mathrm{H}_{2} \mathrm{O}$. Ultraviolet detection wavelength was $338 \mathrm{~nm}$. Free amino acids were assayed on a refractive index detector (Agilent), and peak quantity and identity were obtained by comparison with standards.

Carbohydrates (glucose, fructose, and sucrose) in roots of tall fescue were extracted according to Fu and Dernoeden (2008). Dry samples were ground in liquid nitrogen and sieved with 40-mesh sieve. $0.1 \mathrm{~g}$ of subsamples was used for extraction; then, $1 \mathrm{~mL}$ ethanol $(92 \%, \mathrm{v} / \mathrm{v})$ was added and tubes were shaken vigorously for $10 \mathrm{~min}$. Then the samples were centrifuged at $20,000 \times g$ for $10 \mathrm{~min}$ and the residues were re-extracted twice with the method mentioned above. A pooled supernatant was evaporated to dryness at $40{ }^{\circ} \mathrm{C}$ in an oven, and resolubilized in $300 \mu \mathrm{L}$ deionized water for extraction of glucose, fructose, and sucrose. $0.5 \mathrm{~mL}$ of deionized water was added and the tubes were heated at $100{ }^{\circ} \mathrm{C}$ for $10 \mathrm{~min}$. The mixture was enzymolyzed with $0.1 \mathrm{~mL}$ $\alpha$-amylase $\left(400 \mathrm{U} \cdot \mathrm{mL}^{-1}\right)$ and $0.1 \mathrm{~mL}$ starch transglucosylase $\left(2 \mathrm{U} \cdot \mathrm{mL}^{-1}\right)$ in $0.4 \mathrm{~mL}$ acetic buffer (200 mM, pH 5.1) at $55^{\circ} \mathrm{C}$ for $20 \mathrm{~h}$ and centrifuged at $20,000 \times g$ for $10 \mathrm{~min}$. The supernatant was kept boiled in acid environment $(0.5 \mathrm{M}$ sulfuric acid) for $15 \mathrm{~min}$. The cooled mixture was neutralized with equal sodium hydroxide $(100 \mathrm{~mm})$ and stored at $-20{ }^{\circ} \mathrm{C}$ for further analysis.

Carbohydrates were analyzed by HPLC. The HPLC system equipped with a 515 pump, a 717 autosampler and a 2410 reftactometer was controlled by WATER Empower software. Glucose, fructose, and sucrose were separated on a crest amino column $(4.6 \times$ $250 \mathrm{~mm}, 5 \mu \mathrm{m})$ and eluted isocratically in $40{ }^{\circ} \mathrm{C}$ with the elution buffer [acetonitrile: $\left.\mathrm{H}_{2} \mathrm{O}=1: 1(\mathrm{v} / \mathrm{v})\right]$ at a flow rate of 1.0 $\mathrm{mL} \cdot \mathrm{min}^{-1}$. The carbohydrates were assayed on a refractive index detector, and peak quantity and identity were obtained by comparison with standards.

Statistical analysis. All results from the experiment were expressed as mean of five replicates. The data were analyzed by oneway ANOVA. The mean separation was performed with least significant difference at $5 \%$ probability level using the SAS statistical software package (SAS 9.0 for windows, SAS Institute Inc., Cary, NC).

\section{Results}

There was no significant decline on turf quality in two different saline-soil treatments after two months, when compared with the control plants (Fig. 2A). T30 treatment reduced VSGR relative to the control and T20 treatment (Fig. 2B). T30 treatment reduced root fresh and dry weight relative to the control and T20 treatment for the three layers, while T20 reduced root fresh and dry weight in the bottom layer $(20-40 \mathrm{~cm})$ relative to the control
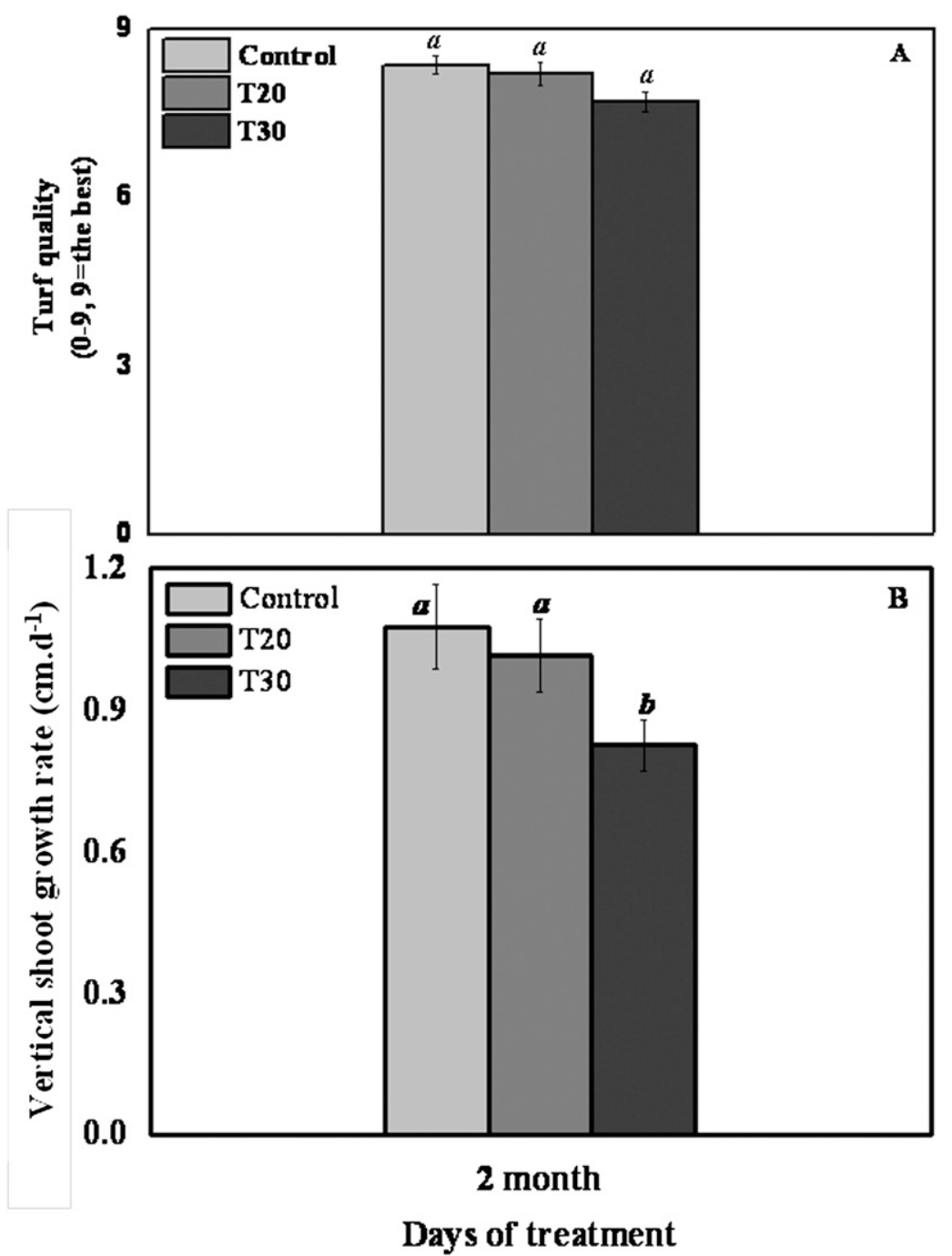

Fig. 2. Effects of different depth of saline soil on turf quality (A) and vertical shoot growth rate (B) of tall fescue. Vertical bars on the top indicate standard deviation, and bars with the same letter indicate no significant difference at $P=0.05$ for the comparison of treatment at a given day.

plants (Fig. 3). Total root length in T30 was $30.0 \%$ and $24.3 \%$ lower than that of control and $\mathrm{T} 20$, respectively (Table 1$)$. Total root projected areas of T30 and T20 were $44.9 \%$ and $22.5 \%$ lower than the control (Table 1). The root diameters of T30 and T20 were $23.8 \%$ and $17.5 \%$ lower than that of the control, respectively.

Saline soil significantly increased root activity in the 0-10 cm soil layer, which were 1.6and 1.4-fold higher than that of the control in T30 and T20, respectively (Fig. 4). In the 10 $20 \mathrm{~cm}$ soil layer, T30 reduced the root activity relative to the control and T20 (Fig. 4). In the $20-40 \mathrm{~cm}$ soil layer, root activity decreased with the increase of saline soil in PVC tubes, which decreased to $69 \%$ and $46 \%$ of the control plants in T20 and T30, respectively (Fig. 4).

The T30 treatment increased the free amino acids in roots of tall fescue, including aspartic-acid (Asp), glutamic-acid (Glu), serine (Ser), glycine (Gly), threonine (Thr), arginine (Arg), lactamine (Ala), methionine (Met), leucine (Leu), and lysine (Lys) relative to the control and T20 treatment, except for Arg and Lys (Table 2). However, there were no significant differences in free amino acids between the control and T20 treatment (Table 2).

Soluble sugars (sucrose, glucose, and fructose) accumulated with the increasing of saline soils in roots of tall fescue. T30 treatment increased the root sucrose, glucose, and fructose content relative to the control and T20 treatment in the three soil layers $(0-10,10-20$, and $20-40 \mathrm{~cm})$. However, T20 treatment increased the root sucrose, glucose, and fructose only in the middle $(10-20 \mathrm{~cm})$ and bottom $(20-40 \mathrm{~cm})$ soil layers, when compared with the control plants (Fig. 5).

\section{Discussion}

High salinity stunted plant growth by inciting ionic and osmotic stresses (Allakhverdiev et al., 2000; Jia et al., 2011; Khaled et al., 2003; Zhu, 2001). In addition, high salinity stress had adverse effect which could create ionic toxicity and secondary stresses (Dat et al., 2000; Hu et al., 2011). They would result in inhibition of plant growth, accompanied with reductions in root biomass, and 


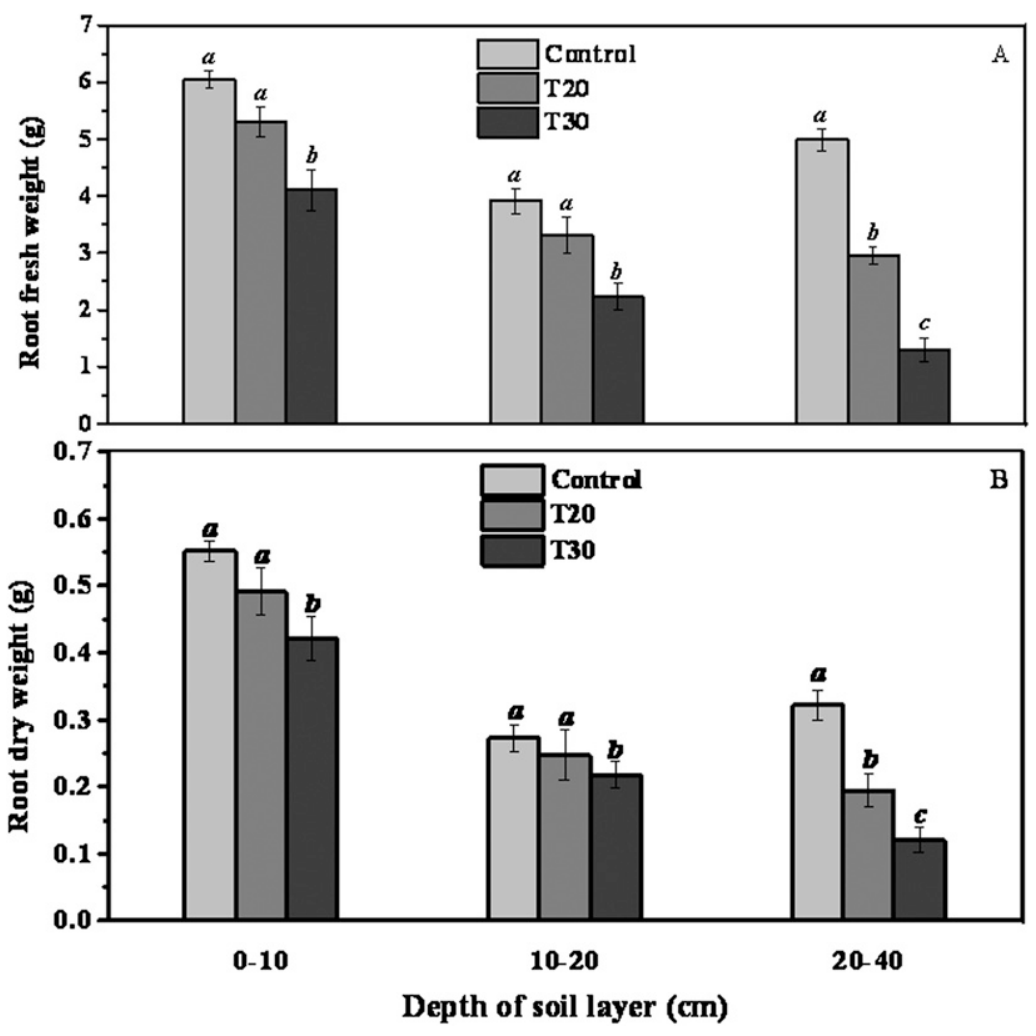

Fig. 3. Effects of different depth of saline soil on root fresh weight (A) and root dry weight (B) of tall fescue. Vertical bars on the top indicate standard deviation, and bars with the same letter indicate no significant difference at $P=0.05$ for the comparison of treatment at a given depth of soil layer.

Table 1. Effects of different depth of saline soil on total root length, total root projected area, and average root diameter of tall fescue.

\begin{tabular}{lccc}
\hline Treatments & Total root length $(\mathrm{cm})$ & Root projected area $\left(\mathrm{cm}^{2}\right)$ & Root diam $(\mathrm{cm})$ \\
\hline Control & $6196.8 \mathrm{a}$ & $381.6 \mathrm{a}$ & $0.063 \mathrm{a}$ \\
T20 & $5732.4 \mathrm{a}$ & $295.6 \mathrm{~b}$ & $0.052 \mathrm{~b}$ \\
T30 & $4336.6 \mathrm{~b}$ & $210.4 \mathrm{c}$ & $0.048 \mathrm{~b}$ \\
\hline
\end{tabular}

Values $(n=5)$ followed by the same letters within a column means no significant difference between treatments based on least significant difference test at $P=0.05$.

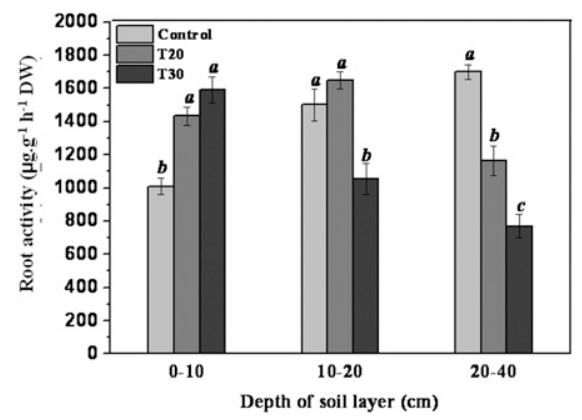

Fig. 4. Effects of different depth of saline soil on root activity of tall fescue. Vertical bars on the top indicate standard deviation, and bars with the same letter indicate no significant difference at $P=0.05$ for the comparison of treatment at a given depth of soil layer.

even leading to death because of nutritional metabolism disorder (Mohammad et al., 1998; Trapp et al., 2008). Tall fescue subjected to high salinity in deep soil exhibited a decrease in VSGR (Fig. 2B), although no significant difference between T20 and
1994). Higher root activity designated greater ability to absorb water and nutrients and hence faster growth rate (Ruf and Brunner, 2003). Salt stress and ionic toxicity may result in a decline of root vigor. Minimum level of root dehydrogenase activity had been reported in many studies (Islam et al., 2007; Li et al., 2005). While Yi et al. (2007) had showed that the root activity in three desert halophyte species significantly increased with the increase of salinity concentration. In this study, we observed that root activity in tall fescue surviving in saline-soil condition drastically reduced. Therefore, high salinity would decrease the root activity, while root activity from the mixtures of sand and organic materials had a significant increase (Fig. 4). These may be adaptive responses of tall fescue to deep soil salinity by metastasis of the active site on roots and a high density of new roots in upper soil layer with lower salinity (Table 3 ).

Amino acids are required for protein synthesis and serve as precursors for many metabolites with multiple functions in plant growth and responses to various stress conditions (Less and Galili, 2008). The functions of free amino acids could be attributed to its role in osmotic adjustment, hydroxyl radical scavenger, sink for energy, and metabolism to regulate redox potentials, and nitrogen source for rapid growth after salinity stress (Matysik et al., 2002; Parida and Das, 2005; Rai, 2002; Sairam et al., 2002). In our study, free amino acids content increased in salinesoil treated roots of tall fescue. Compared with other amino acids, three types of amino acids, namely Asp, Gly, and Glu, increased dramatically in roots from T30. In previous study, Glu and Gly were the fundamental metabolites in the chlorophyll synthesis process, and in plants proline is synthesized mainly from glutamate (Kannangara et al., 1988; Szabados and Savoure, 2010). Accumulation of Glu and Asp had been reported in plants exposed to salinity stress (Dubey, 1997; Mansour, 2000). Lea et al. (2007) reported that Glu and Asp were the major transport compounds and nitrogen stores in plants. The accumulation of Asp, Gly, and Glu induced by high salinity stress suggest that they participate in more vital physiological-biochemical reactions in tall fescue, and are crucial for adaptive responses and regulative mechanisms of tall fescue under high salinity in deep soil.

A strong correlation between soluble sugars accumulation and osmotic stress tolerance had been discovered in transgenic plant materials (Taji et al., 2002). Higher carbohydrates concentration before and during abiotic stress indicates improved tolerance (Kafi et al., 2003). Salinity stress induced an accumulation of soluble sugars which might contribute to salinity tolerance by avoiding metabolic alterations (Pattanagul and Thitisaksakul, 2008). Soluble sugars, including fructose, glucose, and sucrose, in salinity stressed plants are essential for osmotic adjustment, osmoprotection, and carbon storage for energy and metabolism (Kerepesi 
Table 2. Effects of different depth of saline soil on the content of free amino acids in the roots of tall fescue from the top layer $(0-10 \mathrm{~cm})$.

\begin{tabular}{lcccccccccc}
\hline & \multicolumn{8}{c}{ Free amino acids content $\left(\mathrm{mg} \cdot \mathrm{g}^{-1} \mathrm{FW}\right)$} \\
\cline { 2 - 10 } Treatments & Asp & Glu & Ser & Gly & Thr & Arg & Ala & Met & Leu & Lys \\
\hline Control & $4.14 \mathrm{~b}$ & $3.98 \mathrm{~b}$ & $2.93 \mathrm{~b}$ & $1.96 \mathrm{~b}$ & $1.76 \mathrm{~b}$ & $6.84 \mathrm{~b}$ & $1.76 \mathrm{~b}$ & $0.56 \mathrm{~b}$ & $1.17 \mathrm{~b}$ & $1.26 \mathrm{~b}$ \\
T20 & $4.84 \mathrm{~b}$ & $4.73 \mathrm{~b}$ & $3.09 \mathrm{~b}$ & $2.53 \mathrm{~b}$ & $2.36 \mathrm{~b}$ & $7.26 \mathrm{ab}$ & $1.58 \mathrm{~b}$ & $0.66 \mathrm{~b}$ & $1.22 \mathrm{~b}$ & $1.56 \mathrm{ab}$ \\
T30 & $8.24 \mathrm{a}$ & $7.26 \mathrm{a}$ & $4.52 \mathrm{a}$ & $5.28 \mathrm{a}$ & $3.36 \mathrm{a}$ & $8.87 \mathrm{a}$ & $3.22 \mathrm{a}$ & $1.15 \mathrm{a}$ & $1.51 \mathrm{a}$ & $1.85 \mathrm{a}$ \\
\hline
\end{tabular}

Values $(n=5)$ followed by the same letters within a column means no significant difference between treatments based on least significant difference test at $P=0.05$.

Table 3. Changes of soil total soluble salt content before experiment and after harvest.

\begin{tabular}{|c|c|c|c|c|c|c|}
\hline \multirow[b]{3}{*}{ Treatment } & \multicolumn{6}{|c|}{ Total soluble salt (\%) } \\
\hline & \multicolumn{2}{|c|}{$0-10(\mathrm{~cm})$} & \multicolumn{2}{|c|}{$10-20(\mathrm{~cm})$} & \multicolumn{2}{|c|}{$20-40(\mathrm{~cm})$} \\
\hline & Initial & Final & Initial & Final & Initial & Final \\
\hline Control & $0.21 \mathrm{Aa}$ & $0.23 \mathrm{Ab}$ & $0.20 \mathrm{Ab}$ & $0.25 \mathrm{Ac}$ & $0.21 \mathrm{Ab}$ & $0.24 \mathrm{Ac}$ \\
\hline T20 & $0.20 \mathrm{Aa}$ & $0.37 \mathrm{Ab}$ & $0.21 \mathrm{Bb}$ & $0.75 \mathrm{Ab}$ & $2.51 \mathrm{Aa}$ & $0.92 \mathrm{Bb}$ \\
\hline T30 & $0.20 \mathrm{Ba}$ & $0.58 \mathrm{Aa}$ & $2.50 \mathrm{Aa}$ & $0.93 \mathrm{Ba}$ & $2.50 \mathrm{Aa}$ & $1.68 \mathrm{Ba}$ \\
\hline
\end{tabular}

Means $(n=5)$ followed by different letters for soil $\mathrm{NaCl}$ content are significantly different based on least significant difference test at $(P=0.05)$. Lowercase letters $(\mathrm{a}, \mathrm{b}, \mathrm{c})$ stand for comparison within a column between different treatments, and uppercase letters (A, B) stand for comparison within a row only between the results from the same soil layer before experiment and after harvest.
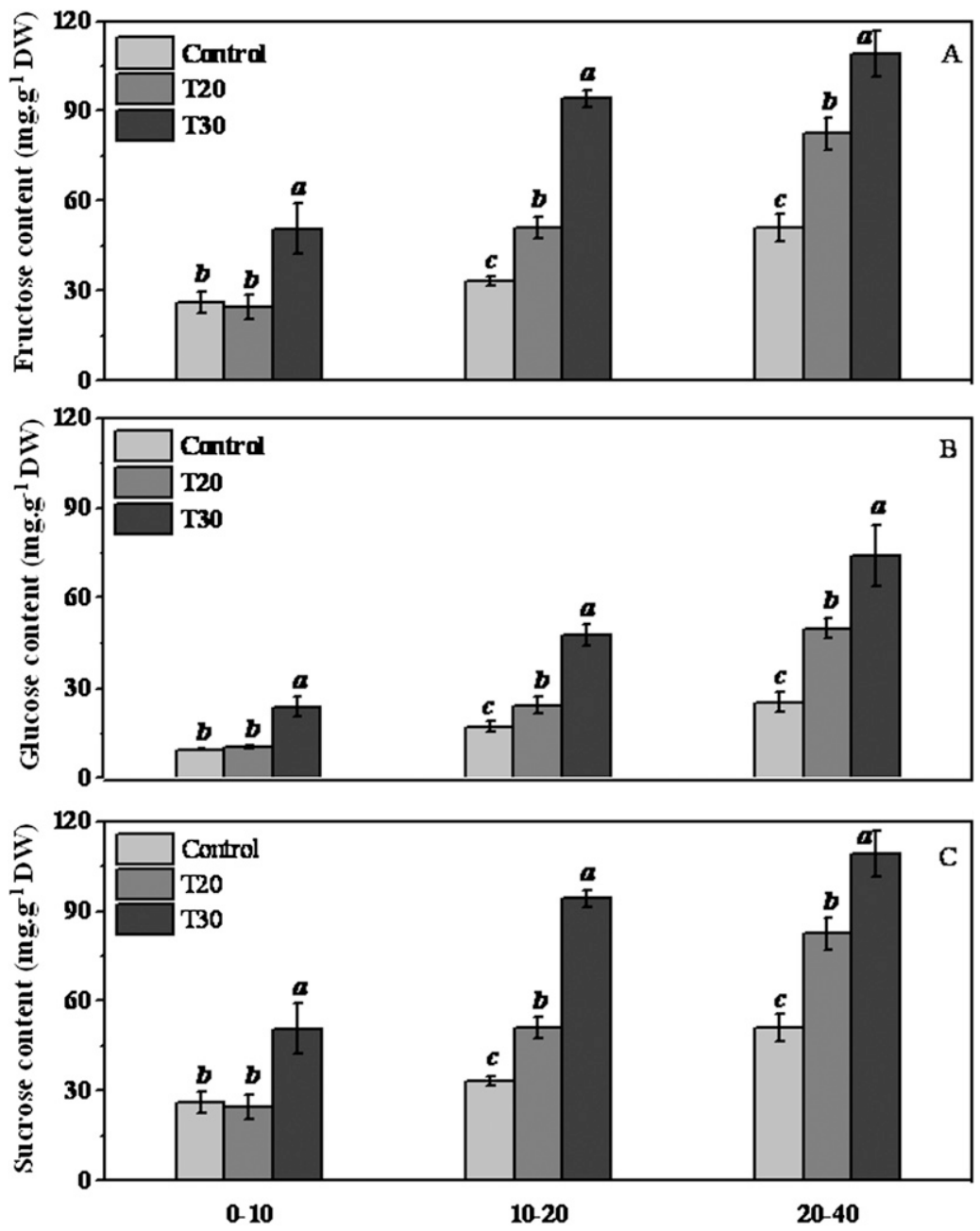

Depth of soil layer (cm)

Fig. 5. Effects of different depth of saline soil on the content of fructose (A), glucose (B), and sucrose (C) in the roots of tall fescue from different soil layers. Vertical bars on the top indicate standard deviation, and bars with the same letter indicate no significant difference at $P=0.05$ for the comparison of treatment at a given depth of soil layer.

and Galiba, 2000), and they may be effective candidates for antioxidant stress in plant tissues through sugar signaling and triggering the production of specific ROS scavengers (Van den Ende and Valluru, 2009). Soluble sugars in plant roots were either from photo- synthate translocation from leaves or the degradation of high molecular compound and synthesis by itself (Robbins and Pharr, 1988). A few studies suggest that soluble sugars contents like fructose and glucose may decrease because of the photosynthesis limitation process and plant growth inhibition under salt stress (Hu et al., 2013; Zhang et al., 2012). On the contrary, more studies found that soluble sugars increase in plants when they are exposed to abiotic stresses (Hoch et al., 2002; Kafi et al., 2003; Kerepesi and Galiba, 2000). In our research, we observed that the fructose, glucose, and sucrose contents in roots of tall fescue accumulated with the depth of saline soil. As mentioned above, water was sprayed every $2 \mathrm{~d}$, and tall fescue exhibited a high turf quality (scoring 7-8, full score is 9, Fig. 2A) without leaf death. Since the leaves had no morphological damage (by observation), we suggested there was minimum or no photosynthesis limitation. Under deep soil salinity conditions, tall fescue roots were the first site to be in contact with the salt in the soil, and hence the first organs to make adaptive responses against this abiotic stress. Furthermore, due to water leakage, the upper soil layer had lower salt level while the deeper soil layer had a higher salt concentration (Table 3). Root growth was inhibited by high salt concentrations, which resulted in the accumulation of metabolites. On one hand, soluble sugars might have served in osmotic adjustment and osmoprotection to salinity stress; on the other hand, they also might be used as carbon storage for energy and as carbon skeleton for metabolisms to prepare for adequate metabolic matters and energy for new root growth after salinity stress.

In summary, the saline-soil treatments incited root growth inhibition in tall fescue. Under high salinity in deep soil condition, the growth and elongation of roots was inhibited, and root biomass was significantly lower and the root system became thinner. Simultaneously, the concentration of free amino acids (Asp, Glu, Gly, etc.) and soluble sugars (fructose, glucose, and sucrose) increased in roots. Root activity in deeper soil layer (full of saline soil) was drastically reduced. However, in roots from upper soil layer (filled with mixtures of sand and organic materials) it increased significantly. The accumulation of soluble sugars in roots exposed to saline-soil layer and the increasing root activity and free amino acids in roots on nonsaline-soil layer were adaptive responses and regulative mechanisms for supporting the above-ground plant growth in tall fescue to cope with high salinity in deep soil. In addition, our studies suggest that a $20 \mathrm{~cm}$ mixture of sand and organic materials could supply basic space for root growth of tall fescue with regular spray irrigation when exposed to deep soil salinity.

\section{Literature Cited}

Allakhverdiev, S.I., A. Sakamoto, Y. Nishiyama, M. Inaba, and N. Murata. 2000. Ionic and osmotic effects of $\mathrm{NaCl}$-induced inactivation 
of photosystems I and II in Synechococcus sp. Plant Physiol. 123:1047-1056.

Barnett, N.M. and A.W. Naylor. 1966. Amino acid and protein metabolism in bermuda grass during water stress. Plant Physiol. 41:1222-1230.

Khaled, L.B., A.M. Gomez, E.M. Ouarraqi, and A. Oihabi. 2003. Physiological and biochemical responses to salt stress of mycorrhized and/or nodulated clover seedlings (Trifolium alexandrinum L.). Agronomie 23:571-580.

Bilgin, O., I. Baser, K.Z. Korkut, A. Balkan, and N. Saglam. 2008. The impacts on seedling root growth of water and salinity stress in maize (Zea mays). Bulg. J. Agric. Sci. 14:313-320.

Cheong, M.S. and D.J. Yun. 2007. Salt-stress signaling. J. Plant Biol. 50:148-155.

Clemenssonlindell, A. 1994. Triphenyltetrazolium chloride as an indicator of fine-root vitality and environmental-stress in coniferous forest stands: applications and limitations. Plant Soil 159:297-300.

Dat, J., S. Vandenabeele, E. Vranova, M. Van Montagu, D. Inze, and F. Van Breusegem. 2000. Dual action of the active oxygen species during plant stress responses. Cell. Mol. Life Sci. 57:779-795.

Martino, C.D., S. Delfine, R. Pizzuto, F. Loreto, and A. Fuggi. 2003. Free amino acids and glycine betaine in leaf osmoregulation of spinach responding to increasing salt stress. New Phytol. 158:455-463.

Dubey, R. 1997. Photosynthesis in plants under stressful conditions, p. 859-875. In: Pessarakli, M. (ed.). Handbook of photosynthesis. Marcel Dekker, New York, New York.

Farooq, M., A. Wahid, D.J. Lee, O. Ito, and K.H.M. Siddique. 2009. Advances in drought resistance of rice. Crit. Rev. Plant Sci. 28:199-217.

Fu, J. and P.H. Dernoeden. 2008. Carbohydrate metabolism in creeping bentgrass as influenced by two summer irrigation practices. J. Amer. Soc. Hort. Sci. 133:678-683.

Gilbert, G.A., M.V. Gadush, C. Wilson, and M.A. Madore. 1998. Amino acid accumulation in sink and source tissues of Coleus blumei Benth. during salinity stress. J. Expt. Bot. 49:107-114.

Greenway, H. and R. Munns. 1980. Mechanisms of salt tolerance in non-halophytes. Annu. Rev. Plant Physiol. Plant Mol. Biol. 31:149-190.

Hasegawa, P.M., R.A. Bressan, J.K. Zhu, and H.J. Bohnert. 2000. Plant cellular and molecular responses to high salinity. Annu. Rev. Plant Physiol. Plant Mol. Biol. 51:463-499.

Hoagland, D.R. and D.I. Arnon. 1950. The waterculture method for growing plants without soil. California Agr. Expt. Stat. 347:1-32.

Hoch, G., M. Popp, and C. Korner. 2002. Altitudinal increase of mobile carbon pools in Pinus cembra suggests sink limitation of growth at Swiss treeline. Oikos 98:361-374.

Hu, T., H.Y. Li, X.Z. Zhang, H.J. Luo, and J.M. Fu. 2011. Toxic effect of $\mathrm{NaCl}$ on ion metabolism, antioxidative enzymes and gene expression of perennial ryegrass. Ecotoxicol. Environ. Saf. 74:2050-2056.

Hu, T., L.X. Hu, X.Z. Zhang, P.P. Zhang, Z.J. Zhao, and J.M. Fu. 2013. Differential responses of $\mathrm{CO}_{2}$ assimilation, carbohydrate allocation and gene expression to $\mathrm{NaCl}$ stress in perennial ryegrass with different salt tolerance. PLoS ONE 8:e66090.

Islam, E., X. Yang, T.Q. Li, D. Liu, X.F. Jin, and F. H. Meng. 2007. Effect of Pb toxicity on root morphology, physiology and ultrastructure in the two ecotypes of Elsholtzia argyi. J. Hazard. Mater. 147:806-816.

Jia, J., X.J. Cui, J.H. Wu, J.Y. Wang, and G.Z. Wang. 2011. Physiological and biochemical responses of halophyte Kalidium foliatum to salt stress. Afr. J. Biotechnol. 10:11468-11476.

Kafi, M., W.S. Stewart, and A.M. Borland. 2003. Carbohydrate and proline contents in leaves, roots, and apices of salt-tolerant and saltsensitive wheat cultivars. Russ. J. Plant Physiol. 50:155-162.

Kannangara, C.G., S.P. Gough, P. Bruyant, J.K. Hoober, A. Kahn, and D. Vonwettstein. 1988. Transfer Rna-Glu as a cofactor in deltaaminolevulinate biosynthesis-steps that regulate chlorophyll synthesis. Trends Biochem. Sci. 13:139-143.

Kerepesi, I. and G. Galiba. 2000. Osmotic and salt stress-induced alteration in soluble carbohydrate content in wheat seedlings. Crop Sci. 40:482-487.

Kerkeb, L. and U. Krämer. 2003. The role of free histidine in xylem loading of nickel in Alyssum lesbiacum and Brassica juncea. Plant Physiol. 131:716-724.

Koca, H., M. Bor, F. Ozdemir, and I. Turkan. 2007. The effect of salt stress on lipid peroxidation, antioxidative enzymes and proline content of sesame cultivars. Environ. Expt. Bot. 60:344-351.

Lea, P.J., L. Sodek, M.A.J. Parry, P.R. Shewry, and N.G. Halford. 2007. Asparagine in plants. Ann. Appl. Biol. 150:1-26.

Lee, S.H., J.H. Choi, W.S. Kim, T.H. Han, Y.S. Park, and H. Gemma. 2006. Effect of soil water stress on the development of stone cells in pear (Pyrus pyrifolia cv. 'Niitaka') flesh. Sci. Hort. 110:247-253.

Less, H. and G. Galili. 2008. Principal transcriptional programs regulating plant amino acid metabolism in response to abiotic streses. Plant Physiol. 147:316-330.

Li, T.Q., X.E. Yang, X.F. Jin, Z.L. He, P.J. Stoffella, and Q.H. Hu. 2005. Root responses and metal accumulation in two contrasting ecotypes of Sedum alfredii Hance under lead and zinc toxic stress. J. Environ. Sci. Health A 40:1081-1096.

Lutts, S., M. Almansouri, and J.M. Kinet. 2004. Salinity and water stress have contrasting effects on the relationship between growth and cell viability during and after stress exposure in durum wheat callus. Plant Sci. 167:9-18.

Mansour, M.M.F. 2000. Nitrogen containing compounds and adaptation of plants to salinity stress. Biol. Plant. 43:491-500.

Matysik, J., B.A. Bhalu, and P. Mohanty. 2002. Molecular mechanisms of quenching of reactive oxygen species by proline under stress in plants. Curr. Sci. India 82:525-532.

Mohammad, M., R. Shibli, M. Ajlouni, and L. Nimri. 1998. Tomato root and shoot responses to salt stress under different levels of phosphorus nutrition. J. Plant Nutr. 21:1667-1680.

Munns, R. 2002. Comparative physiology of salt and water stress. Plant Cell Environ. 25:239-250.

Munns, R. 2005. Genes and salt tolerance: Bringing them together. New Phytol. 167:645-663.

Munns, R. and M. Tester. 2008. Mechanisms of salinity tolerance. Annu. Rev. Plant Biol. 59:651-681.

Parida, A.K. and A.B. Das. 2005. Salt tolerance and salinity effects on plants: A review. Ecotoxicol. Environ. Saf. 60:324-349.

Pattanagul, W. and M. Thitisaksakul. 2008. Effect of salinity stress on growth and carbohydrate metabolism in three rice (Oryza sativa L.) cultivars differing in salinity tolerance. Indian J. Exp. Biol. 46:736-742.

Rai, V.K. 2002. Role of amino acids in plant responses to stresses. Biol. Plant. 45:481-487.

Robbins, N.S. and D.M. Pharr. 1988. Effect of restricted root-growth on carbohydratemetabolism and whole plant-growth of cucumis-sativus L. Plant Physiol. 87:409-413.
Rolland, F., E. Baena-Gonzalez, and J. Sheen. 2006. Sugar sensing and signaling in plants: Conserved and novel mechanisms. Annu. Rev. Plant Biol. 57:675-709.

Ruf, M. and I. Brunner. 2003. Vitality of tree fine roots: Reevaluation of the tetrazolium test. Tree Physiol. 23:257-263.

Sairam, R.K., K.V. Rao, and G.C. Srivastava. 2002. Differential response of wheat genotypes to long term salinity stress in relation to oxidative stress, antioxidant activity and osmolyte concentration. Plant Sci. 163:1037-1046.

Serraj, R. and T.R. Sinclair. 2002. Osmolyte accumulation: Can it really help increase crop yield under drought conditions? Plant Cell Environ. 25:333-341.

Szabados, L. and A. Savoure. 2010. Proline: A multifunctional amino acid. Trends Plant Sci. 15:89-97.

Taji, T., C. Ohsumi, M. Seki, S. Iuchi, K. YamaguchiShinozaki, and K. Shinozaki. 2002. Important roles of drought- and cold-inducible genes for galactinol synthase in stress tolerance in Arabidopsis thaliana. Plant Cell Physiol. 29:417426.

Takahashi, M., H. Nakanishi, S. Kawasaki, N.K. Nishizawa, and S. Mori. 2001. Enhanced tolerance of rice to low iron availability in alkaline soils using barley nicotianamine aminotransferase genes. Nat. Biotechnol. 19:466-469.

Tamura, F., K. Tanabe, and M. Katayama. 1995. Relationship between water tolerance and cyanide-resistant respiration in pear rootstocks. J. Jpn. Soc. Hortic. Sci. 64:47-53.

Trapp, S., D. Feificova, N.F. Rasmussen, and P. Bauer-Gottwein. 2008. Plant uptake of $\mathrm{NaCl}$ in relation to enzyme kinetics and toxic effects. Environ. Expt. Bot. 64:1-7.

Turkan, I. and T. Demiral. 2009. Recent developments in understanding salinity tolerance. Environ. Expt. Bot. 67:2-9.

Tejada, M., C. Garcia, J.L. Gonzalez, and M.T. Hernandez. 2006. Use of organic amendment as a strategy for saline soil remediation: Influence on the physical, chemical and biological properties of soil. Soil Biol. Biochem. 38:1413-1421.

Van den Ende, W. and R. Valluru. 2009. Sucrose, sucrosyl oligosaccharides, and oxidative stress: Scavenging and salvaging? J. Expt. Bot. 60:9-18.

Verslues, P.E. and R.E. Sharp. 1999. Proline accumulation in maize (Zea mays L.) primary roots at low water potentials. II. Metabolic source of increased proline deposition in the elongation zone. Plant Physiol. 119:1349-1360.

Wilkins, P.W. and M.O. Humphreys. 2003. Progress in breeding perennial forage grasses for temperate agriculture. J. Agr. Sci. 140:129-150.

Xing, Y., U. Frei, B. Schejbel, T. Asp, and T. Lubberstedt. 2007. Nucleotide diversity and linkage disequilibrium in 11 expressed resistance candidate genes in Lolium perenne. BMC Plant Biol. 7:43.

Xiong, Y.W., S.Z. Fei, R. Arora, E.C. Brummer, R E. Barker, G.W. Jung, and S.E. Warnke. 2007. Identification of quantitative trait loci controlling winter hardiness in an annual perennial ryegrass interspecific hybrid population. Mol. Breed. 19:125-136.

Yi, L.P., J. Ma, and Y. Li. 2007. Impact of salt stress on the features and activities of root system for three desert halophyte species in their seedling stage. Sci. China Ser. D 50:97-106.

Zhang, P.P., J.M. Fu, and L.X. Hu. 2012. Effects of alkali stress on growth, free amino acids and carbohydrates metabolism in Kentucky bluegrass (Poa pratensis). Ecotoxicology 21:19111918.

Zhu, J.K. 2001. Plant salt tolerance. Trends Plant Sci. 6:66-71. 